\title{
Gender Differences in Communication Styles: Implications for Classroom Teaching In Nigerian Schools
}

\author{
Subuola Catherine Abosede, $\mathrm{PhD}$ \\ Department of Educational Management and Business Studies, Faculty of Education, \\ Olabisi Onabanjo University, Ago-Iwoye, Ogun State, Nigeria.
}

\begin{abstract}
Understanding brings about the realization of goals and objectives of the schools which can be achieved through effective communication. In the teaching-learning situation, mutual interaction must occur between the teacher and the students in form of meaningful communication. However, teachers are faced with a lot of barriers which affect the process of imparting the necessary skills, ideas, attitudes, knowledge and the right values in the students. Gender factor is seen in this paper as one of the barriers affecting effective communication in the school and this has to do with the unequal treatments of boys and girls by their teachers in the classroom teaching, which teachers at times are not aware of. Gender differences in communication styles need to be checked for teaching-learning process to achieve its purposes. This paper therefore focuses on communication in the classroom, communication barriers affecting classroom teaching, comparisons between male and female students' communication styles, and finally, steps in promoting communication effectiveness in teaching.
\end{abstract}

Keywords: Gender, Communication, Communication Styles, Communication Barriers, Classroom Teaching.

\section{Introduction}

Good writing and speaking skills are very crucial in our educational system. Whatever the educational goals might be, they can only be attained much faster if there is a mutual interaction or effective communication between the teacher and the students. This interaction, which is one of the aims of communication, is expected to translate into positive achievement of the instructional objectives and in particular, the attainment of the school's main goal and objective. This simply means that, a teacher who is familiar with the aims and objectives of education, curriculum, syllabus, and lesson contents also needs to work out the techniques to be used in transmitting and/or inculcating the necessary skills, ideas, attitudes, knowledge and the right values to the students. This is aimed at bringing about a change in the behaviour of the students and the achievement of the school objectives. To attain these goals therefore, there is the need for an effective communication to take place. However, most of the time, the attainment of these objectives/goals of teaching-learning process faces a lot of challenges or is hampered by a number of factors. One of such factors is gender, which is a global contemporary issue. In the communication styles of teachers, it has been observed that teachers unconsciously treat boys and girls differently in the teaching-learning process. This is because of the socialization process, which stems from factors within the society. The society-based factors, according to Burnley (1996), are the products of the socialization process which start from birth. Certain attitudes and values are considered appropriate as behaviour for both sexes as well as appropriate activities for men and women and the premium placed on them. These factors ranged from parental and teachers' biases, outright discrimination due to taboos, customs and traditional practices and culture.

Gender differences in communication needs to be checked for teaching-learning process to achieve its purposes. Also, to ensure that women who constitute an increasingly large proportion of the labour force are not kept at a primitive level of development and economic life, thereby succeeding in keeping half of humanity tied to the starting point, while the other half runs it (The Guardian, Saturday, February 13, 1988, cited in Abosede, 2010). This implies that boys and girls will automatically grow into men and women who will both contribute to the development of the nation. It is in view of this that teachers need to equip themselves with appropriate communication styles of dealing with the challenges that might arise in the classroom teaching and learning activities so as to provide the needed conducive climate for both boys and girls in the realization of the objectives of the schools. Thus, this paper tries to examine the definition of communication, communication in the classroom, communication barriers affecting classroom teaching, comparisons between male and female students' communication styles, and finally, steps in promoting communication effectiveness in teaching.

\section{The Meaning of Communication}

Communication is difficult to define, even though we communicate all the time. The universality of the term has led to many and varied definitions. Ugboajah (1985) for instance, defined communication as a process which involves all acts of transmitting messages to channels which link people, to the language and symbolic 
codes which are used in transmitting messages, the means by which messages are received and stored, and the rules, customs and conventions which define and regulate human relationships and events. Oyedijo (1995) also defined the term communication as the process of carrying information to people and creating understanding among them in order to influence their behaviour. It is the transfer of information from one person to another, to make certain that their thoughts are completely understood. Communication as defined by Onifade (2001) is seen as trying to understand people and making an effort to get through them. He said further that it could also mean the totality of all things that one person does when he/she wants to create understanding in the mind of another person. The next definition focuses specifically on communication within the school system. At all levels in the school, among and between principal, vice-principal, teachers, students, parents, non-teaching staff, visitors to the school and others, the communication process is continuously in action, which involves exchange of information in order to initiate action or solve a problem. It may involve giving notices about activities, events, decisions and tasks which affect individuals or groups. It also suggests the sharing of opinions and ideas openly and freely, being mindful of other's views and encouraging individuals to seek for information and advice. It could be inferred that to communicate is to share facts or feelings, to make common and to share meaning together. It is not only a one-way affair from a source/sender to receive but it entails a critical feedback component without which its effectiveness is incomplete. It is the process of transmitting meaning from sender to receiver. Communication does not take place unless the receiver correctly interprets the information being transmitted. Communication therefore, is successful to the extent to which the sender of a message and receiver, have a very similar comprehension of the content of the message for the achievement of a desired action, purpose or objective.

\section{Communication in the Classroom}

A teacher can have great influence on the students not only by his actions but also by what he says. The students notice everything the teacher does and says and they copy a great deal of these. It therefore, means that the teacher must possess the ability to explain things in a simple, clear and imaginative manner, which will bring better understanding of the content of the lesson to the students. Language is the chief means through which the teacher communicates with the students (as with other human beings). It is important therefore that the teacher must master the language of communication very well.

In the classroom situation, we see the teacher as the source/sender/encoder of a message. Messages can take the form of order, advice, songs, imparting of knowledge, skills, attitudes, information and must be meaningful and useful to enable the students (receivers) comprehend the message from the teacher (sender). The teacher must have a good knowledge of the language of instruction for the students to actually benefit from the message. For effective communication (teaching) to take place, the teacher must have good knowledge of linguistics, which is made up of grammar, semantics and phonology.

The child naturally learns by paying attention to what is being taught or said. The voice of the teacher must therefore, be clear and audible to capture the attention of the students which must be suitable to their age and level for effective communication to be achieved.

However, communication takes other forms apart from words of our mouth. Awoniyi (1979) said that we communicate through our general behaviour and modes of dress, which dictates what we are, or what we would like to be to other people. In other words, we learn a great deal from the communication we receive or send. The key position of the teacher necessitates his use of thousands of words, as well as communicating by other non-verbal process. This is supported by Jibowo and Oladunjoye (2000) when they say that the teacher must be aware that his or her personality, that is, appearances, dressing behaviour, interaction habits and mannerisms in a way, sends some messages to the learners. Therefore, for the education system to yield the desired results there is the need for more attention to be paid to enhancing the communicative ability of teachers, notwithstanding their areas of specialization. It is based on this that Akinmayowa (1999) said that effective communication is a process based on a number of rational steps which ought to be learned and logically followed. This being the case, it is imperative that teachers be trained in the process of effective communication. This training must focus specifically on factors hindering effective communication at the level of individual since communication is mainly concerned with inter-personal relationships.

The teacher opens up a network of communication by asking the questions, or advising, instructing, giving orders. He can do these with the whole class (group) or an individual. The students also must communicate with the teachers and with one another in various ways and forms, and at different times. When we view these activities, we can say that communication in the classroom is a two-way communication.

In the classroom, communication takes place when there is;

(i) the message to be sent:- body of knowledge, songs, poem, ideas, thoughts, skills

(ii) the sender of the message:- the person to initiate the communication process - the teacher, principal

(iii) the medium by which the message is sent: - speech, writing, relay of a tape recording, charts and so on

(iv) the receiver:- the recipient of the message - the students 
(v) the medium by which the message is received:- the message being heard, read, seen, smelt or touched, imagined, imitated, done.

\section{Communication Barriers Affecting Classroom Teaching}

There are communication barriers a teacher may come up with. He may not be conversant with the content of the lesson (message) and may therefore give out wrong or misleading information in the lesson. The teacher may not be competent and skillful in his command and use of the medium, which he uses in teaching or sending the message. For instance, if the teacher has not mastered the language of instruction, usually English or mother tongue, he will have difficulties in communicating good ideas to his students.

The message being sent to the students may be irrelevant, meaningless or inappropriate to the receiver. Some teachers, to impress, teach difficult and irrelevant topics or teach the aspects of the syllabus they know which may not suit the age, interest, motive or needs of the students. The students (receivers) may never understand the lesson. Without understanding there can be no proper or effective communication (learning). It is the duty of the teacher to pass understandable message to the students. The students should be trained and encouraged to ask questions. This is a feedback mechanism to show that both the teacher and the students have similar understanding of the message. Noise (distortion) may filter with communication. This could be physical noise such as noise from the other classes; people passing by, the market, air field, and football field will surely course distraction. It could be disability of hearing in the students. A teacher may also use a language that is well above and beyond the ability of his students; he may be too fast for the slow learners to absorb what is being taught. It could also be psychological noise, in which the students might lack interest in the lesson, boredom might have set in, or they have just been punished. It is the duty of the teacher to try as much as possible to eliminate all factors that may impede/hinder effective communication with his lesson / class.

Communication goes beyond giving and receiving of information in the class. A good teacher must inform the principal about what goes on in the class and with the children. He must periodically inform parents of their children's progress and problems, invite them for discussion, comments, observation for talking and checking students' work. The teacher also communicates with his colleagues within and outside the school, and with educational officials. In effect, a good teacher must keep open all the channels of communication available to him for the realization of the educational objectives. The barriers to effective communication in the classroom setting can further be seen in the unequal treatment of boys and girls by the teacher in the classroom teaching. This, then, becomes the basis for the gender difference in the communication styles of boys and girls.

\section{School as an Influence on Gender Development}

Gender issue, which is a perception of the preference of sex has been a contemporary one. Contemporary because there exists a divide regarding what constitutes gender - biological classification or psychological description bothering on personality, or a combination of the two (Abosede, 2010). Socialization process has acted as a barrier to girls. This, to a very large extent, stems from factors within the society. The society-based factors, which have inhibited girls' effective participation in school activities, have been identified by Burnley (1996) as a product of a socialization process which starts from birth.

Socialization according to Etaugh and Bridges (2006) refers to the process by which each generation passes along to children the knowledge, beliefs, and skills which constitute the culture of the social group. Societies somewhat prescribe different social roles for adult females and males, girls and boys and differently socialized to prepare them for the adult roles they will play (Lott \& Maluso, 2001; Pomerantz, Ng. \& Wang, 2004). This implies that gender is a social construct. A variety of sources help shape the behaviours and interests of boys and girls. These include parents, teachers, peers, and the media. Based on the focus of this paper therefore, the school factor is of importance in examining the difference in the communication styles of boys and girls in the classroom setting. The educational settings unconsciously convey powerful messages to students about gender typing. The social structure of the school is biased. Generally, more women than men hold most of the low-paying primary school teaching positions, while in the higher-paying school teaching jobs, especially secondary and tertiary institutions men occupy more than half of these positions than do women. Ruble and Martin (1998) added to this by asserting that men are more often in the leadership positions of principal and superintendent. This invariably means that men hold more power than women. In the classroom, teachers often treat girls unequally with their boys counterparts. The American Association of University Women (AAUW, 1992) conclusively reported in their review of over 1,000 publications on girls and education, which was also in conjunction with a more recent meta-analysis of empirical researches conducted by Jones and Dindia (2004) discovered that teachers pay far less attention to girls than to boys. Myra Sadker and David Sadker (1994) found that teachers call on boys more often and give them more time to answer questions. They reported further that boys are more likely to be praised, corrected, helped, and criticized constructively. All these we know, help to promote student learning. Girls on the other hand are more likely to receive a mild and vague "okay" or "yes" response. Teachers most often are more likely to accept a challenge to a duel from boys during a class 
discussion or argument, while their girls' counterparts are reprimanded or corrected for the same behaviour. Teachers reward boys for being smart, while girls are rewarded for being neat, pretty, and compliant. In addition, teachers are likely to give girls the answer when they ask for help but tend to help boys use strategies to figure out the answer themselves (DeZolt \& Hull, 2001).

It is quite unfortunate to note that, teachers are generally not aware that they treat boys and girls differently. This unequal treatment between the two sexes may eventually contribute to the declining self-esteem of adolescent girls if they are not adequately checked. Also, girls are also short-changed in school textbooks, which often ignore or stereotype females (AAUW, 1992; DeZolt\& Henning-Stout, 1999). Worksheets and other teaching materials may also show such biases. For example, a worksheet was given to a student to take home from school to work on. At the left hand side of the sheet were the pictures of a girl and a boy. At the right hand were various pictures of people of different professions such as, a nurse, a doctor, a farmer, a tailor, a teacher, a lawyer, an engineer and a pharmacist. The instructions given to the student were to draw a line from the picture of the girl to the careers that belong with her, and a line from the boy to the careers that go with him. In the child's home where the mother is an engineer and her aunt a medical doctor, the child drew the lines according to what operates in her home and she received an ' $F$ ' on the worksheet. The mother was very upset with the outcome of this. This simply shows the gender biases that some occupations are meant for boys, while some are for the girls.

\section{Comparisons: Male and Female Students' Communication Style}

Spender (1979) as quoted in Popp (2003) and Etaugh and Bridges(2006) reported that, "... feminine talk is a lot of polite talk about silly things; whereas masculine talk is a little blunt talk about important things".

Generally, people have this believe that men have demanding voices, swear, are straight to the point, forceful, and boastful. Women, on the other hand, are thought to talk a lot, speak politely and emotionally, enunciate clearly, use good grammar, talk about trivia things, and gossip a lot (Popp, 2003). Gay (1992) asserted that men and women are so different in their communication styles. He concluded that it is as if "Men are from Mars", "Women are from Venus". Let us now see what different scholars have to tell us about the differences between the communication styles of females and males:

\section{Verbal Communication Style}

Empirical evidence abounds and supports a number of differences in gender talkativeness. Nevertheless, females and males talking behaviour is the opposite of the stereotype attached to the two sexes that, females talk more than the males. However, it has been discovered in many researches conducted in this area, that males talk, speak more frequently and even for longer periods of time than do females. Furthermore, Carli and Bukatko (2000) Kramarae (2001) and Gleason and Ely (2002) reported that gender difference is apparent as early as the pre-school years and continues throughout adulthood. Ezewu (1989) attributes this gender difference to the cultural orientation whereby girls, as part of the home chores training are taught the arrangement and classification of things in an orderly and matching set at home. This, he concluded by saying that, it provides them with much practical training in classification and discrimination.

In gender difference in talkativeness, males are more likely to interrupt others more than females do. Research findings have revealed that gender difference in the number of interruptions is based on the situations and also that women and men have different goals when they interrupt others (Gleason \& Ely, 2002). There are two main reasons for interruption as identified by Etaugh and Bridges (2006). One reason is to show interest and corroborate what the other person is saying - this is called affiliative interruption - for example, by saying "uhhuh". The second reason could be to usurp the floor and control the conversation - which is called intrusive interruption. This could be achieved by taking over the conversation even when the previous speaker did not show any signs of relinquishing the floor. Eckert and McConnell - Ginet (2003), Athenstaedt, Haas and Schwab (2004) and Leman, Ahmed and Ozarow (2005) were all of the view that females are more likely to engage in affiliative interruption and males, in intrusive interruption. It could be inferred that the differences in the interruption of the two sexes are found to be in line with both the social construction of females as other directed and caring and the gender inequality in power. Affiliative interruptions is aimed at showing concern in other people, and females might have learned through their socialization period that this was one way of showing interest about and reinforcing others. Intrusive interruptions and talkativeness are linked with the intention to maintain dominance and with the power to do so. Individuals who are more powerful are seen as having the right to dominate the conversation and to take over the floor forcefully. This is corroborated by the study of Cashdan (1998), who discovered that the more powerful students were the ones who talked the most.

There is also the influence of gender difference in conversational style. Studies reveal that females use more emotional, polite, soothing and supportive speech while males use more direct, goal - oriented, and abrupt 
speech (Kramarae, 2001; Mulac, Bradac \& Gibbons, 2001; Leaper, 2004; Leaper \& Smith, 2004). As an example further given by them, that women are more likely than men to refer to emotions, and use intensive adverbs, like "she is really friendly", whereas men tend to use directives like "Working can be a drag" more than women do. Women also use appropriate personal pronouns than do men (Brownlow, Rosamond \& Parker, 2003; Pennebaker, Mehl\& Niederhoffer, 2003).

In conversational style, Mulac (1998), Carli and Bukatko (2000) and Goldshmidt and Weller (2000) reported that, females use a more tentative speech which may be made up of:

uncertainty verbs - "It seems that the class will be interesting"

hedges - "I kind of feel you should not be too upset about this"

tag questions - "It's hot in here, don't you think?"

disclaimers of expertise - "I may be wrong, but..."

Gender differences in speech as explained further by Lakoff (1990) that, females speak more tentatively than do males because females have lower self-esteem than males. However, Weatherall (2002) interpreted women's tentativeness as a result of women's lower status. This implies that women use more tentative language in their conversations with men rather than when they interact with females.

Adepoju (1996) shares the view of Terman and Tyler (1954) that boys and girls have differential abilities. He argues that boys are superior in numerical aptitudes, science, reasoning and spatial relationships while girls are superior in verbal fluency, perceptual speed, memory and manual dexterity. In support of this assertion is the view of Kinura (1969), that females have a slight edge over males in language performance. Carol and Carol (1977) contend that English Language is majorly a female subject since girls perform better in it than boys. Ezewu (1989) asserted that women are less active than men and discuss a lot, while men are hyperactive and act out a lot. MacGeorge as cited by Mulac (1998), argues that gender differences in communication style is difficult to detect, and that it is difficult to identify the gender of speakers simply from their words. Mulac in an attempt to determine the gender of a communicator, asked some students to read a written communication and identify the gender of the writer. He discovered that they could not guess accurately the gender of the communicator. He conclusively reported that, "spoken and written language used in every day communication by men and women, as well as girls and boys, display a high degree of similarity".

\section{Non-Verbal Communication Style}

In line with the shared stereotype believes, females are seen as more likely than males to engage in non-verbal behaviours that demonstrate interpersonal interest and warmth. Research evidence has considerably shown that this finding was observed to be true. According to Goldshmidt and Weller (2000) and Hall, Carter and Horgan (2000), women and girls are more likely than men and boys to engage in mutual eye contact with another individual for longer periods of time, particularly if that individual is female. Gender difference in gazing behaviour according to Leeb and Rejskind (2004) did not appear at birth but manifests as early as 13 weeks of age and goes on to adulthood. Hall et al (2000) reported that females also smile, lean forward more, and approach others more closely. Girls and women are more likely than boys and men to be sensitive to the meanings of non-verbal messages portrayed by others and more accurately interpret their emotions (Brody \& Hall, 2000).

Also, in a study on interpersonal sensitivity, it was reported that females are better than males at initially getting to know the personality traits, emotional states, and behavioural tendencies of other people. Horgan, Schmid Mast, Hall and Carter (2004), all concluded that women are more accurate at recalling the appearance of social targets. Differential socialization of females and males brought into focus these gender differences, with the females receiving greater societal encouragement for being socially concerned (McChire, 2000). Smiling and gazing communicate interest and involvement in another person. In addition, women's ability to successfully understand other people's emotional states might develop from their greater interest in others and their more extensive experience with emotional communication.

Another explanation of females' superior sensitivity skills can be found in their subordinate status/roles within the society. To adapt very well socially, LaFrance (2001) says that less powerful people must be good interpreters of the nonverbal cues of more powerful people. He concluded that they must be able to anticipate the reactions of those with power. In other words, women are more likely to successfully understand the nonverbal behaviour of others which might serve as a protective mechanism that guides the interpersonal relationships of all lower-status individuals, women inclusive.

Nonverbal communication could also take the form of touch. The framework for understanding gender differences in the sense of touch was proposed by Nancy Henley (1995). She reported that there is an unwritten societal rule that high-status individuals can touch low-status individuals, but those of low-status cannot touch those of high status. For example, it is more likely that the teacher in the classroom will pat a student on the back than the reverse. Henley conclusively reported that males have a greater degree of power than females, 
hence there is more male-to-female touching than the reverse. However, research in the area, has provided mixed findings, with no overall gender differences in touching (Hall, 1996).

Use of sense of touch in communication are of different types - hugs that depict affection, to inappropriate sexual touching that is harassing, to formal handshakes that communicates respect. There is a mixed finding in the researches in the overall gender difference in touching. But interestingly, one investigation, suggests an interesting relationships among gender, status, and touching. In conclusion, gender and status differences in touching are more complex than were originally believed. And finally, other variables, such as age and type of relationship can also affect who touches whom (Hall \& Veccia, 1992).

\section{Steps in Promoting Communication Effectiveness in Teaching}

While it is true that the teacher can do only so much to control any communication situation, he/she is far from helpless. With study and practice of communication, the teacher can greatly improve his/her skills and turn them into valuable career assets. The teacher should therefore start his/her study with an overview of the five Ws, one H, and I and two Qs.

i. Who Your Audience Is: The status of the teacher in relation to his audience (students) is a major factor in setting a tone and establishing a power balance. Communication styles must be adjusted to accommodate different audiences (students) irrespective of gender.

Let us consider these two scenarios:

(a) You teach in a private secondary school. This morning you call a reluctant student who has no exercise book for the lesson. You tell the student that the exercise book must be bought and brought to school the next day or he will not be allowed to attend the lesson.

(b) Later in the day you approach your principal and request for an exercise book to write your lesson-note.

These two situations involve requests for exercise books and you feel entitled to receive the exercise books from the two parties.

There are some factors that the teacher must consider because his attitude and tone are likely to differ in the way he addresses these two people, neither will he talk to the principal the same way with the student. He needs to consider the human dimension because each person is a separate entity, similar to the teacher in some ways and different in some other ways. People react differently to messages because their perception is filtered through their individual personalities and experiences, such as; age, gender, race, income level, marital status, intelligence, physical condition and so on.

A teacher should realize that he can expect different types of behaviour from different students and make allowances of these differences, that is, treat each student as individual that must be respected. For any meaningful communication to take place therefore, the teacher needs to know among other things, the students intimately, their background, knowledge of the message (content of the lesson) learning difficulties, interest and others.

As a teacher therefore, you must be aware of the existence of the personal circumstances of the students and tailor your actions accordingly. Empathy, goodwill, and good manner are the tools of the teacher for keeping the interpersonal channels open.

ii. What You Are Saying: What will the effect of your message (teaching of the lesson content) be on the students? Will they care to listen? Will they find it acceptable or threatening? Students are much more receptive if they agree with the teacher or if they can see some benefits they can get from the message. The teacher must try to determine what the students' interests are and analyse the probable results of what he says well before he says it.

For instance, you are planning to introduce in your class the weekly test. This idea is sound and promising to develop the mental ability of the students.

The problem is that the students might not see anything good about this plan and might view it in light of their personal interests, in terms of who will pass and who will fail, which students will be promoted and which ones will be downgraded or asked to repeat. These and similar questions will be foremost in their minds. The objective merit of your plan will receive secondary or partial consideration among the students. This plan might be good news to the school authorities, but will not look good for the students who will be writing tests every week. Try to determine ahead of time what the result of your message will be.

iii. Why You Are Talking: There are only two good reasons for teaching; meeting the school's objectives in an effective and efficient manner and imparting in the students' the relevant knowledge, skills and attitudes. Be honest about your motivations. If the main purpose of your teaching is to blow off-steam or impress the students with ambiguous words, then the lesson is probably not worth teaching. When teaching, you deal with students of different backgrounds and individual differences - differences in environment, ability, physical appearance, moral, social and emotion. Don't waste their time or confuse them with unnecessary talk. 
iv. When the Communication Takes Place: Have you chosen an opportune moment to get your ideas/thoughts across? Do the receivers (students) have time or in the mood to listen? Even the best lesson will fail if the timing is wrong. Bad timing can result in ugly communication failures, such as the following situation:

You are a Mathematics teacher in a secondary school. Your teaching periods have been fixed for afternoon periods. What do you think the reaction/ feedback of the students is likely to be?

Mathematics by nature is an intellectual and technical subject which requires good mental alertness. The subject is best taught in the morning when the students have not tasked their brain so much. The reaction of the students to Mathematics being taught in the afternoon is that with poor mental set comprehension/understanding of the lesson will be distorted or hindered.

v. Where the Communication Takes Place: Physical surroundings can be very important. Teaching is much more successful when it is taught in a comfortable environment. Where would it be better to teach - in a noisy environment or in a quiet, confined and conducive classroom? For teaching-learning situation to be effective and successful, the teacher must arrange a conducive and attractive environment, a place where learning could be very comfortable.

vi. How the Messages Is Conveyed: Is it written or spoken? What format will your teaching take - discussion method, demonstration, writing, debates, project, role-playing, discovery, inquiries, activity method, use of questions etc.? Is the chosen format the best that is available for the situation? The choice of medium largely depends on the subject-matter. It will be absurd for a Mathematics teacher to assess his students' ability of the content of the lesson or learning using oral questions. The students are expected to acquire the ability to define or recognize symbols (language of Mathematics). It is equally important for them to acquire the Mathematics skills of solving problems.

The only best way in assessing students' ability to solve problems is by solving them, that is, practical solutions to the problems. It is equally unreasonable for a teacher to use radio to discuss a technical matter involving figures with the audience (students).

An I and two Qs can be added to the five Ws and one $\mathrm{H}$.

vii. Importance: Students like to be recognized and feel important. They want to be accepted. Even the most insignificant student is the centre of his/her own universe, however, it might seems ridiculous to any other person else. If a student can be made to feel that he is recognized and important member of the class, the teacher's job as a communicator of ideas will be greatly facilitated.

Even when the teacher is teaching a whole class, he must make each student feel that he/she is being spoken to personally. One way of making the students feel unimportant is by allowing stereotyping to influence one's thinking. This could erase individual differences among students and placing them into common, usually unfavourablemoods.

viii. Quantity: the contents of the messages received by the students on a daily basis are numerous. Therefore, to avoid screening out the great bulk of the knowledge imparted on the students, the teacher should not overdo the length and frequency of their transmission of information to the students so as to preserve their mental harmony. Length and frequency vary with each situation but the minimum is best. The students should not be swamped with more information than they can handle. They have no choice but to screen all and/or the most important information from their minds.

ix. Quality: Every bit of communication between the teacher and the students should be of the highest possible quality. This simply implies that the rules of courtesy and of correct English should be respected. Sloppy, ungrammatical words say unfavourable things about the teacher. A lesson that is boring and poorly organized puts the students in a bad light. The information sent to students must be unmistakably and unambiguously clear. Quality is achieved when the basic unit of written logic, that is, sentence construction is followed. This adds authority to whatever you have to say to the students.

\section{Conclusion}

Gender is a global and contemporary issue which has continued to arouse keen interest of researchers. This could have been as a result of the natural tendencies of human beings to ascribe certain aspects of endeavours, such as technical ones to males while those endeavours seen as being easy, are ascribed to females. Consequently, in the education field, males are believed to have upper edge over females in areas, such as Science, Technology and Mathematics. Females on the other hand are believed to do better than males in Arts and Humanities. This gender bias formed the basis for this write up in relation to communication styles adopted in the classroom/school setting. Communication includes a variety of language skills, such as vocabulary, reading comprehension, writing, spelling, grammar, and word fluency. All the students irrespective of gender must show superior performance in these language skills. It is however, interesting to say that teachers unconsciously treat girls differently from their boys counterparts, even in areas that are ascribed to be female dominated. Teachers call on boys more often while they pay far less attention to girls. Even, in the area of 
research, there is no consensus in the empirical finding of researchers as to which sex out-perform the other with particular reference to communication styles. It is therefore posited that teachers, irrespective of gender and other factors must pay attention to all the students in the classroom teaching and school activities so that the nation's educational goals can be achieved.

\section{References}

[1]. Abosede, S.C. (2010). Gender constructs in the performance of managerial functions in universities in Ogun State. An Unpublished Ph.D. Thesis submitted to the Department of Educational Foundations and Management, Faculty of Education, Olabisi Onabanjo University, Ago-Iwoye, Ogun State, Nigeria.

[2]. Adepoju, A.A. (1996). Sex differences, home background, and pupils' performance in English and Mathematics? In S. Ayodele (Ed.), Education in the service of humanity. Uganda: Educational Research and Study Group. 240-347.

[3]. Akinmayowa, J.T. (1999). Man-in-organisation: A practical approach to the study of human behaviour in organizations. Benin: Nigerian Management Consultancy Forum Educational Resources Centre.

[4]. American Association of University Women (AAUW), (1992). How schools shortchange women: The AAUW Report. Washington, DC: AAUW Educational Foundation.

[5]. Athenstaedt, U., Haas, E., \& Schwab, S. (2004). Gender role self-concept and gender-typed communication behaviour in mixed-sex and same-sex dyads. Sex Roles,50, 37-52.

[6]. Awoniyi, T. (1979). Principles and practice of education. London: Hodder and Stroughton.

[7]. Brody, L.R., \& hall, J.A. (2000). Gender, emotion, and expression. In M. Lewis \& J. Haviland-Jones (Eds.), Handbook of emotions, 2nd ed. (pp. 338-349). New York: Guilford.

[8]. Brownlow, S., Rosamond, J.A., \& Parker, J.A. (2003). Gender-linked linguistic behaviour in television interviews. Sex Roles,49, 121-132.

[9]. Burnley, G.E. (1996). The role and status of African women in society. Paper Presented in a Short Course on Women in Development and Micro-Enterprise Paid 22 April 22, June 1996.

[10]. Carli, L.L., \& Bukatko, D. (2000). Gender, communication, and social-influence: A development perspective. In T. Eckes \& H.M. Trautner (Eds.), The development social psychology of gender (pp. 295-332). Mahwah, NJ: Erlbaum.

[11]. Carol, J.B., \& Carol, B. (1977). Sex differences in English Language achievement of primary school pupils. Journal of Abnormal and Social Psychology,65

[12]. Cashdan, E. (1998). Smiles, speech, and body posture: How women and men display sociometric status and power. Journal of Nonverbal Behaviour,22, 209-228.

[13]. DeZolt, D.M., \& Henning-Stout, M. (1999). Adolescent girls' experiences in school and community settings. In N.G. Johnson, M.C. Roberts, \& J. Worell (Eds.), Beyond appearance: A new look at adolescent girls (pp. 253-275). Washington, DC: American Psychological Association.

[14]. DeZolt, D.M., \& Hull, S.H. (2001). Classroom and social climate. In J. Worell (Ed.), Encyclopedia of women and gender (pp. 257264). San Diego: Academic Press.

[15]. Eckert, P., \& McConnell-Ginet, S. (2003). Language and gender. Cambridge: Cambridge University Press.

[16]. Etaugh, C., \& Bridges, J. (2006). Women's lives: A topical approach. USA: Pearson Education, Inc.

[17]. Ezewu, E.E. (1989). A study of sex differences in academic achievement of secondary school students. The Counsellor,3 (1\&2), 1013.

[18]. Gleason, J.B., \& Ely, R. (2002). Gender differences in language development. In A. McGillicuddy-DeLisi \& R. DeLisi (Eds.), Biology, society, and developmental psychology, Vol. 21 (pp. 127-154). Westport, CT: Ablex.

[19]. Goldshmidt, O. T., \& Weller, L. (2000). "Talking emotions": Gender differences in a variety of conversational contexts. Symbolic Interaction, 23, 117-134.

[20]. Hall, J.A. (1996). Touch, status, and gender at professional meetings. Journal of Nonverbal Behaviour,20, 23-44.s

[21]. Hall, J.A., \& Veccia, E.M. (1992). Touch asymmetry between the sex. In C.L. Ridgeway (Ed.), Gender, interaction, and inequality (pp. 81-96. New York: Springer.

[22]. Hall, J.A., Carter, J.D., \& Horgan, T.G. (2000). Gender differences in nonverbal communication of emotion. In A.H. Fischer (Ed.), Gender and emotion: Social psychological perspective (pp. 97-117). Paris: Cambridge University Press.

[23]. Henley, N.M. (1995). Body politics revisited: What do we know today? In P.J. Kalbfleisch \& M.J. Cody (Eds.), Gender, power, and communication in human relationships (pp. 27-61). Hillsdale, NJ: Erlbaum.

[24]. Horgan, T.G., Schmid Mast, M., Hall, J.A., \& carter, J.D. (2004). Gender differences in memory for the appearance of others. Journal of Personality and Social Psychology Bulletin,30, 185-196.

[25]. Jibowo, A.V., \& Oladunjoye, S.A. (2000). Effective communication in teaching. In S.Y. Erinosho, A. Adesanya \& A. Ogunyemi (Eds.), Teaching effectiveness in Nigerian schools. Ibadan: Sam Bookman Publishers.

[26]. Jones, S.M., \& Dindia, K. (2004). A meta-analytic perspective on sex equity in the classroom. Review of Educational Research, 74, 443-471.

[27]. Kinura, D. (1969). Speech internalization in young children as determined by literature test. Journal of Comparative and Social Psychology, 140, 899-902.

[28]. Kramarae, C. (2001). The third shift: Women learning online. Washington, DC: American Association of University Women.

[29]. LaFrance, M. (2001). Gender and social interaction. In. R.K. Unger (Ed.), Handbook of the psychology of women and gender (pp. 245-255). New York: Wiley.

[30]. Lakoff, R.T. (1990). Talking power: The politics of language. New York: Basic Books.

[31]. Leaper, C. (2004, July). Gender-related variations in affiliative and assertive speech: Meta-analyses. Paper presented at the American Psychological Association Convention. Honolulu.

[32]. Leaper, C., \& Smith, T.E. (2004). A meta-analytic review of gender variations in children's language use: Talkativeness, affiliative speech, and assertive speech. Developmental Psychology,40, 993-1027.

[33]. Leeb, R.T., \& Rejskind, F.G. (2004). Here's looking at you, kid! A longitudinal study of perceived gender differences in mutual gaze behaviour in young infants. Sex Roles, 50, 1-14.

[34]. Leman, P.J., Ahmed, S., \& Ozarow, L. (2005). Gender, gender relations, and the social dynamics of children's conversations. Developmental Psychology, 41, 64-74.

[35]. Lott, B., \& Maluso, D. (2001). Gender development: Social learning. In J. Worell (Ed.), Encyclopedia of women and gender (pp. 537-549). San Diego: Academic Press. 
[36]. McClure, E.B. (2000). A meta-analytic review of sex differences in facial expression processing and their development in infants, children, and adolescents. Psychological Bulletin, 126, 424-453.

[37]. Mulac, A. (1998). The gender-linked language effect: Do language differences really make a difference? In D.J. Canary \& K. Dindia (Eds.), Sex differences and similarities in communication: Critical essays and empirical investigations of sex and gender in interaction (pp. 127-153). Mahwah, NJ: Erlbaum.

[38]. Mulac, A., Bradac, J.J., \& Gibbons, P. (2001). Empirical support for the gender-as-culture hypothesis. An intercultural analysis of male/female language differences. Human Communication research,27, 121-152.

[39]. Onifade, A. (2001). Management: Office, business, education. Abeokuta: KAPPCO Nigeria Limited.

[40]. Oyedijo, A. (1995). Principles of management. Ibadan: Paramount Books Limited.

[41]. Pennebaker, J.W., Mehl, M.R., \& Niederhoffer, K.G. (2003). Psychological aspects of natural language use: Our words, our selves. Annual Review of Psychology, 54, 547-577.

[42]. Pomerantz, E.M., Ng, F.F., \& Wang, Q. (2004). Gender socialization: A parent x child model. In A.H. Eagly, A.E. Beall, \& R.J. Sternberg (Eds.), The psychology of gender (pp. 120-144). New York: Guilford.

[43]. Popp, D. (2003). Gender, race and speech style stereotypes. Sex Roles, 48, 317-325.

[44]. Ruble, D.N., \& Martin, C.L. (1998). Gender development. In W. Damon (Series Ed.) \& N. Eisenberg (Vol. Ed.), Handbook of child psychology. Vol. 3. Social, emotional and personality development, 5th ed. (pp. 933-1016). New York: Wiley.

[45]. Sadker, M., \& Sadker, D. (1994). Failing at fairness: How America's schools cheat girls. New York: Scribner.

[46]. Terman, L.M., \& Tyler, L.E. (1954). Psychological sex differences. In Manual of Child Psychology (2nd ed.). New York: Wiley.

[47]. Ugboajah, F.O. (1985). Communication: An overview. International Keynotes, 1 (1), 2.

[48]. Weatherall, A. (2002). Gender, language, and discourse. London: Routledge. 